\title{
LA CONVERSIÓN DE TERRORISTAS EN ICONOS O EL SÍNDROME DE HEROSTRATOS
}

\author{
Ivan Witker
}

Un extraño halo de romanticismo envuelve los tours de force de aquella violencia política asociada con la "causa justa”, con los desposeídos. Varios de sus intrépidos protagonistas son vistos hoy, en los años de post Guerra Fría, con una fascinación tan creciente como bizarra. Es que la violencia — se advierte en este artículo- puede engendrar figuras carismáticas, susceptibles de ser procesadas como mito y transformadas en objeto de culto. Epítomes son el afiche pop art de Guevara elaborado por Andy Warhol y todo ese mundus sensibilis creado en torno a los líderes de la Rote-Armee-Fraktion, cuya embestida contra el estado de derecho alemán, hace 30 años, parece ya estar adquiriendo tonalidades épicas. Pero hay límites. Las acciones de los suicidas místicos musulmanes son vistas como sacrificios des-individualizados que no provocan más que pánico. No son suelo fértil para la germinación de mitos, condición sine qua non para que el terrorista sea visto como un romántico rebelde. Sólo tienen en común esa dimensión herostratica de la violencia.

IVAn WitKer. Ph.D. por la Universidad Carlos IV, Praga, República Checa. Director de la Cátedra de Relaciones Internacionales de la Academia Nacional de Estudios Políticos y Estratégicos (ANEPE), profesor del Doctorado en Estudios Americanos de IDEA/USACH y profesor de cultura latinoamericana en la Universidad de los Andes, Santiago.

Estudios Públicos, 111 (invierno 2008). 


\section{Guevara: ecce homo, ecce sanctus}

ـa transformación de Ernesto Guevara de la Serna en una divinidad laica se explica tanto por el significado político de su trayectoria como por la persistencia de ciertas imágenes de idealismo que le rodean. Voluntaria o involuntariamente, todas las aproximaciones biográficas han ido gestando una atmósfera de fascinación por una existencia que pareciera bordear la ficción.

El éxito post mortem de Guevara, sin duda, sorprende. Y es que la simple rebeldía de un joven asmático, proveniente de un apacible hogar burgués de la provincia argentina, devenido en un ministro algo inepto en una isla del Caribe, y que acaba sus días en una aventura a todas luces peligrosa, poco ayuda a explicar su carrera póstuma. Por lo tanto, pareciere ser necesario hurgar no sólo en sus cualidades personales y en su trayectoria, sino también en los contextos de las mismas.

Muchos de sus biógrafos rescatan un talento innato, un formidable instinto comunicacional, para captar ciertos mecanismos necesarios en pos de la trascendencia que tanto lo inquietaba ${ }^{1}$. Uno de ellos fue esa capacidad para producir estados febriles en contra del establishment. Por medio de frases sencillas consiguió imponer verdaderos apotegmas en favor de la justicia social, anidándolos en una densa y enardecida atmósfera antinorteamericana. Ninguno de sus famosos locus classicus dejó espacio para la ambigüedad. Como aquel apocalíptico "Crear uno, dos, tres Vietnams”, que cautivó a millones de jóvenes durante los 60 y 70, no sólo en América Latina, y que apuntaba a mirar aquella lejana experiencia bélica como una epopeya ejemplar, digna de emular, aunque ello demandase un fuerte tributo en sangre. Pero la autoglorificación también la buscó por medio de una conducta individual que bordeaba la desmesura. En el fragor de la Sierra Maestra se ganó el respeto del naciente fidelismo con aquella perentoria orden de "Ante la duda, mátalo" dada al entonces tembloroso comandante Ramiro Valdés ${ }^{2}$. Su fama de hombre de decisiones herostraticas ${ }^{3}$ la vivió

\footnotetext{
${ }^{1}$ Línea desarrollada en varios de los textos de Castañeda (2004) sobre Guevara.

2 Por largos años, ministro del Interior. Desde agosto de 2006, ministro de Informática y Telecomunicaciones.

${ }^{3}$ Para efectos operacionales, y por ser éste un ensayo, seguimos a Borowitz (2007) y utilizamos la expresión violencia herostratica, en el entendido que sus protagonistas persiguen la autoglorificación atacando con lógica destructiva puntos simbólicos, icónicos, del mundo que les toca vivir. Tal cual lo hizo Herostratos con su ataque contra el Templo de Artemisa en Efeso en el 356 a.C. Se trata de una expresión asimilable a la acepción que da Polk (2007) a violencia política en orden a entenderla como un instrumento táctico de grupos irregulares que practican la insurgencia, la guerrilla o el terrorismo, independientemente de la frecuencia, intensidad o forma de uso.
} 
más tarde en carne propia Fidel Castro cuando debió aceptar el retiro de los misiles soviéticos tras la aguda crisis vivida entre Moscú y Washington. "Si los cohetes hubiesen permanecido en Cuba, los habríamos utilizados todos y dirigido contra el corazón mismo de los EE.UU., incluida Nueva York”, le espetó al máximo líder ${ }^{4}$. En su discurso ante la Asamblea General de la ONU (1964) Guevara señaló de manera persuasiva, pero amenazante, que "como marxistas hemos sostenido que la coexistencia pacífica entre las naciones no incluye la coexistencia entre explotados y explotadores"5.

Esta fascinación por el juego al límite se advertía ya en sus años juveniles, cuando fue testigo privilegiado del golpe militar en contra de Jacobo Arbenz en Guatemala (1954) y escribía a su madre: “Aquí estuvo todo muy divertido, con tiros, bombardeos, discursos y otros matices que cortaron la monotonía en que vivía”6.

El mito "Guevara” fue construyéndose en consecuencia sobre la base del efecto perviviente de su verbo, pero también de su personalidad y su enorme carisma, descubierto en pleno apogeo revolucionario por el fotógrafo Alberto Korda ${ }^{7}$, quien captó al ya por entonces apodado guerrillero heroico, mientras observaba el paso de un cortejo fúnebre en marzo de

${ }^{4}$ Fue el propio Guevara quien negoció con Nikita Khrushov el despliegue de los 42 misiles nucleares en la isla durante su visita a Moscú. Hay quienes divisan en esta desavenencia el primer síntoma de distanciamiento entre Guevara y Castro. Según Lee Anderson (2002), el largo viaje de catorce meses por África que emprendió Guevara en 1965 obedeció a la molestia que habría ido acumulando Castro en los primeros años de la revolución con la proclividad del guerrillero heroico a ordenar fusilamientos de "elementos contrarrevolucionarios" como se denominaba a la oposición en aquellos años.

${ }^{5}$ Discurso pronunciado en la ONU el 11 de diciembre de ese año.

${ }^{6}$ Citado por Á. Vargas Llosa (2007).

${ }^{7}$ Su nombre real era Alberto Díaz Gutiérrez (1928-2001). Nunca dijo sentir frustración por no recibir pagos de royalty por el uso de la imagen, aun cuando presentó una acusación judicial en Londres en contra de las agencias publicitarias londinenses Rex Features y Lowe Lintas, que utilizaron la citada imagen en un spot para el fabricante de vodka Smirnoff. En un acuerdo extrajudicial le pagaron una indemnización de US\$ 50 mil que donó al Ministerio de Salud de Cuba. Korda fue propietario junto a su amigo Luis Pierce de un conocido estudio fotográfico en La Habana en la década del 50 y tras la instauración del régimen de Fidel Castro pasó a ser reportero gráfico de la revista ilustrada Revolución, siendo más tarde el fotógrafo personal del líder cubano. Otro de sus aciertos es la única foto conocida del líder cubano jugando golf. En 1999 apareció brevemente en la película Buena Vista Social Club de Wim Wenders. Tomó su nombre artístico del cineasta húngaro Alexander Korda, famoso en la Cuba de los años 50. Falleció de un ataque cardíaco en París mientras presentaba una exposición con sus trabajos. Datos extraídos de "Che Guevara photographer dies” BBC News 26 de mayo de 2001 (www.bbc.co.uk) y de Lee Anderson (2006). 
$1960^{8}$. La instantánea se convirtió en uno de los símbolos gráficos del siglo 20 al ser trabajada por el ilustrador irlandés de comics y posters, Jim Fitzpatrick, impregnándole gruesos contrastes rojo, negro y blanco ${ }^{9}$. Fue esa imagen kordiana, fuertemente contrastada por Fitzpatrick, la que utilizó Andy Warhol para elaborar un cuadro con nueve imágenes dispuestas de manera cuadriculada de $3 \times 3$ en diversos colores y tonalidades, y que tras ser incluidas en las muestras y exposiciones de Warhol, cobró notoriedad mundial. Los trazos pop art en su rostro terminaron siendo clave para que millares de personas descubrieran, cual objeto de culto, a este individuo algo exótico, capaz de una audacia, tan difícil de conmensurar, como fue la instalación de focos insurreccionales en lugares muy dispersos del planeta, como República Dominicana, Argentina, Argelia, Panamá, Venezuela y el Congo, so pretexto de exportar justicia social. Aquella imagen warholiana hizo amigable a un hombre "de características superiores", dispuesto a

${ }^{8}$ El 5 de marzo de 1960, la nave belga "Le Coubre” (en algunos textos mencionada como "La Coubre"), que había arribado al puerto de La Habana transportando 76 toneladas de armas y municiones compradas por el regimen de Fidel Castro en Amberes, sufrió un grave acto de sabotaje donde murieron 136 personas. Korda fue enviado por su revista a cubrir las ceremonias fúnebres ya que asistían importantes invitados del recién instaurado régimen revolucionario, entre ellos Jean Paul Sartre y Simone de Beauvoir. Guevara apareció brevemente en dicha ocasión, y Korda le tomó dos fotos con una máquina marca Leica. La revista, sin embargo, escogió para su portada otra foto, tomada también por Korda, donde Castro aparecía departiendo con Sartre. El fotógrafo se llevó las dos instantáneas de Guevara a su estudio, donde las tuvo colgadas hasta 1967, cuando recibió la visita de un dirigente del Partido Comunista cubano acompañado del magnate de las comunicaciones italiano, Giacomo Feltrinelli, por ese entonces financista del Partido Comunista de su país, quien venía procedente de Bolivia, donde había iniciado negociaciones para obtener la liberación del intelectual francés Regis Debray, por quien se había enterado que el foco guerrillero que asolaba a ese país estaba dirigido por el ya mítico Guevara. Feltrinelli, dotado de un gran instinto para los negocios, andaba a la búsqueda de fotos del líder guerrillero para utilizarlos en los lienzos, posters y demás material de propaganda que demandaban las crecientes y masivas manifestaciones estudiantiles de ese año. Feltrinelli, un virtuoso para transformar en dinero todo tipo de memorabilia comunista, había causado molestia en la dirigencia moscovita en los años previos al sacar clandestinamente de la capital soviética la versión original de Dr. Zhivago, la conocida novela del disidente Boris Pasternak, publicarla y distribuirla comercialmente en Occidente. Apenas se supo la noticia de la muerte de Guevara, Feltrinelli imprimió millones de afiches con la foto de Korda. Luego, la influyente revista francesa Paris Match publicó el 21 de octubre de 1967 un reportaje titulado "Los Guerrilleros Heroicos”, en el que aparece la foto del Che tomada por Korda. Este reportaje a la vida de Guevara tuvo gran éxito y por ende la imagen de Korda se difundió ampliamente en el convulsionado mayo del 68 francés. Datos extraídos de “Guevara’s image saved from drink” BBC News 15 de septiembre de 2000 (www.bbc.co.uk) y de Lee Anderson (2006).

${ }^{9}$ Jim Fitzpatrick utilizó el estilo pop art de tintas planas, sin dibujo y efectos muy expresivos visualmente. La imagen de colores planos, en blanco y negro sobre fondo rojo, se distribuyó desde Irlanda a todos los movimientos estudiantiles del 68. 
proezas tan difíciles de asir, como mirar globalmente el tema de los desvalidos, y, más aún, deponer los naturales conflictos hamletianos cuando se aproximaron las disputas por el liderazgo revolucionario en $\mathrm{Cuba}^{10}$.

Y es que habitualmente a un líder guerrillero, especialmente aquel que ha encabezado un movimiento de liberación nacional, se le plantea una disyuntiva que no todos resuelven de manera acertada, entre ser un revolucionario eterno o convertirse en fundador de un Estado. Guevara optó por lo primero. Pero su opción no fue un viaje a la conspiración eterna, sino a la transformación en un gran seductor de los desvalidos del mundo. Se propuso transmitir la idea - muy popular en esos años- que los individuos revolucionarios son mejores que el común de los mortales. Esa audaz combinación le terminaría reservando un lugar especial en el execrable universo de caudillos latinoamericanos. Esa es la característica que rescata, en un veinteañero Guevara, la cinta "Diarios de Motocicleta” (2004), y que preanunció el film "Che!” en 196911.

Desde luego que consustancial al mito fue su transformación en santo laico en Cuba hacia mediados de los 70 . Fue por aquellos años, cuando el régimen percibió que el quijotismo de Guevara podría servir de elemento amalgamador de toda la experiencia fidelista, necesaria para enfrentar los síntomas de agotamiento revolucionario. Recurrir a la figura de Guevara fue un ejercicio terapéutico. Su imagen sirvió para que las generaciones más jóvenes tuviesen una visión epopéyica de la Sierra Maestra y para que el vulgo cubano entendiese aquella exógena noción del internacionalismo proletario con la que se justificaba por aquellos años el envío masivo de tropas cubanas a Angola, Etiopía y otros países africanos. Premonitoriamente, Guevara se había adelantado a aquello al organizar guerrillas multina-

${ }^{10}$ Un caso emblemático es su relación con el periodista argentino Jorge Ricardo Massetti. Nacido en Avellaneda, Buenos Aires en 1929, Massetti entrevistó a Fidel Castro y a Guevara en la Sierra Maestra, estableciendo una estrecha relación con este último, quien lo instó a regresar a La Habana si se producía el triunfo de la revolución. De vuelta en la capital cubana, crea en 1961, por instrucciones de Guevara, la agencia de noticias Prensa Latina. En 1963, Guevara le sugiere que se marche a combatir a Argelia contra las fuerzas colonialistas francesas como una forma de entrenamiento antes de partir a Argentina para crear el primer foco insurreccional en ese país. En la norteña localidad de Salta, Massetti funda el Ejército Revolucionario del Pueblo y asume como "Comandante Segundo" (en el entendido que Guevara se plegaría al mismo apenas se consolidara el foco, asumiendo obviamente como "Comandante Primero"). Massetti desapareció en abril de 1964, estimándose que en esa fecha perdió la vida en alguno de los escasos choques con Gendarmería argentina en la selvática localidad de Oran.

11 "Diarios de Motocicleta" fue dirigida por el brasileño Walter Salles y protagonizada por Gael García en el papel de Guevara. "Che!” fue dirigida por Richard Fleischer y tuvo a Omar Sharif en el papel de Guevara y a Jack Palance en el de Fidel Castro, siendo el primer intento biográfico de Guevara llevado al cine. 
cionales en ese continente. Los escolares cubanos fueron conminados a identificarse con el grito “¡Seremos como el Che!”; su nombre empezó a retumbar por las escuelas y aulas de la isla. Su santificación, que podría interpretarse como un perspicaz gesto retributivo de los hermanos Castro frente al abandono voluntario del liderazgo de parte de Guevara, comenzó a ganar fuerza con el paso del tiempo al incrustarse el guerrillero heroico en el imaginario de los rebeldes del mundo entero, lo que motivó la necesidad de construirle un punto de peregrinaje. Por eso, el régimen no vaciló en trasladar a Cuba los huesos encontrados en 2005 en el lugar de su muerte en Bolivia, brindándole funeral de Estado y convirtiendo su mausoleo en La Meca del sentimiento rebelde.

El capitalismo fue transformando la figura de Guevara en un objeto de culto de manera paulatina. Comenzó a simplificar su identidad, procurando una des-cubanización estilizada y universalizando ese rostro warholiano-kordiano ${ }^{12}$.

Apareció un hommo, dotado de la capacidad de despertar sentimientos definidos, contestarios, contra legem. Un objeto de culto mercantilizado de la rebeldía etérea, difusa, pero inequívoca. Surgió un sanctus, capaz de aglutinar, de proyectar sensaciones individuales y grupales. Nació un universo de sensaciones guevarianas.

Un primer haz de sensaciones lo perciben individuos que necesitan sentirse parte de un colectivo altamente politizado, cumpliendo tareas épicas, llenas de dificultades y hasta incomprensiones, pero seguros de ir por "el camino correcto". Para ellos, Guevara simboliza la existencia perenne de un nuevo comienzo y el convencimiento de que las dificultades políticas son siempre cíclicas, donde lo fundamental está dado por la relación individuo-grupo. Aquí, el gran apotegma guevariano es: "el deber de todo revolucionario es hacer la revolución”. Éste es el Guevara que admiran los líderes de la Rote-Armee-Fraktion y tantos otros grupos violentistas posteriores. Ésta es la figura que totemiza el líder de la RAF, Andreas Baader, en su celda en Stammheim y hoy decora la intimidad de los nostálgicos de los socialismos reales.

Un segundo haz de sensaciones irrumpe entre aquellos que ven en Guevara una figura esclarecedora, conductualmente excelsa, de rasgos cuasi ignacianos, que supera el ámbito de la política y que, por lo mismo, sirve como elemento de orientación vital. Son sensaciones que lo perciben como

${ }^{12}$ En el sitio de en.wikipedia.org, bajo el criterio de búsqueda "Che Guevara in popular culture” aparece un listado de situaciones concretas —películas, televisión, moda, música, libros, revistas, turismo, avisos comerciales, teatro, artes visuales, juegos y política - influidas por el nombre o fotografías de Guevara. 
un macho alfa, capaz de atisbar un horizonte lejano —quimérico—, en pos de un "hombre nuevo", de una sociedad mejor.

Luego, un tercer haz llega a quienes lo perciben como un ser definitivamente superior, protector, comprensivo con quienes sienten inclinaciones irrefrenables por adentrarse en vericuetos y aventuras, por vociferar irreverencias. Es un validador de anti-convencionalismos. Ello explica que seres que disfrutan de una existencia llevada al límite, como Mike Tyson o Diego Maradona, desgañitan su admiración tatuándose la imagen de Guevara.

El universo de sensaciones permite constatar que Guevara ha devenido en un objeto de culto extraordinariamente dúctil, que abandona las estrechas circunstancias del foquismo guerrillero y se proyecta con fuerza hacia un futuro de mayor espectro, pero que, a la vez, emerge cual símbolo de la contra-cultura; algo que realza el guión de la cinta "Che” de Steven Soderbergh, aclamado en el Festival de Cannes (mayo 2008).

Producto de estas sensaciones, el hommo deviene en sanctus. Desde luego que sin la democracia ni la economía de mercado, la expansión de este universo de sensaciones guevarianas habría sido imposible. La democracia permite el culto póstumo, pues se ha vuelto inocuo. La economía de mercado lo ha transformado en un simple bien de consumo. Es un hommo, y a la vez un sanctus. Es la figura central para quienes buscan aquello que Nietzsche llamaba aspectos dionisíacos de la existencia y que, en contraposición a los apolíneos, priorizan la imaginación, los deseos primarios de querer que el mundo sea distinto a como realmente es.

\section{RAF: Herostratos juvenil}

¿Jóvenes idealistas?, ¿'rostros y cuerpos de la contra-cultura?, ¿insurrectos instrumentalizados por la URSS y la RDA?, ¿idólatras de la violencia al servicio del terrorismo árabe?, ¿simples fanáticos obsesionados con el quiebre generacional? A treinta años del clímax terrorista alemán, estas preguntas tan claves sobre la naturaleza del principal grupo violentista contemporáneo de aquel país, la Rote-Armee-Fraktion (RAF), conocido también como Baader-Meinhof, no tienen respuestas claras. Algunos juegan con un silencio aún doliente; otros se esfuerzan por buscar interpretaciones convincentes, mientras que los deudos de las víctimas y sobrevivientes siguen manifestando enojo e insatisfacción respecto a cómo el Estado de derecho 
alemán —el Rechtsstaat — respondió ante este tan dramático como abstruso casus belli de los $70^{13}$.

En efecto, la nebulosa que se posó sobre la sociedad germana frente a éste, el principal desafío terrorista de la postguerra, le ha dificultado, por un lado, dimensionar los diversos asuntos que conlleva el problema, y, por otro, la hizo sentirse insatisfecha con el trabajo desplegado por sus órganos de inteligencia, policiales y judiciales. A treinta años de la llamada Ofensiva 77 desatada por la RAF, sus ecos retumban periódicamente. Se les considera ya inocuos. Pero el trauma re-vive de cuando en cuando con el retorno paulatino desde la clandestinidad de antiguos miembros del mismo, o cuando algunos de sus remanentes presos buscan salir en libertad, sea pidiendo indultos presidenciales o entregando nuevos antecedentes sobre casos no cerrados judicialmente, sin mostrar arrepentimiento por sus conductas de antaño. El interés de ciertos literati en procesar artísticamente la brutal experiencia de este grupo se percibe necesario, pero quizás algo prematuro. Ello quedó fuertemente ilustrado el otoño de 2003, cuando una retrospectiva gráfica sobre los principales líderes de la RAF, a realizarse en Berlín y financiada con recursos públicos, desató una agria polémica ${ }^{14}$.

La discusión sobre dicha retrospectiva focalizó la atención sobre un asunto de relevancia y validez universal, que dice relación con las características que debe reunir el momento a partir del cual un hecho político, signado con sangre, puede ser examinado con perspectiva netamente histórica y ser procesado a través de diversas manifestaciones del arte, sin reabrir heridas.

La complejidad del problema deriva de la constatación que la RAF fue, en aspectos cuantitativos, uno de los grupos terroristas más efectivos de su época. Actuó en un lapso que comprende la segunda mitad de la década del 60 hasta cuando se declaró autodisuelto según un comunicado de prensa remitido a la agencia Reuters el 20 de abril de 1998, dejando tras sí 34 personas asesinadas, la mayoría personalidades prominentes de la socie-

${ }^{13}$ Michael Buback, hijo del asesinado Fiscal Federal General, ha seguido el caso judicial relacionado con su padre, ya que nunca se ha logrado establecer quién de todos los detenidos fue el autor material. En una extensa entrevista sobre el punto, Buback señala que el hecho y sus consecuencias han sido un "sueño maligno" que ha perseguido a su familia desde entonces, Sontheimer (2007). Igualmente ilustrativa es la entrevista a Monika Harms, Fiscal Federal General en 2007, en la que ella plantea la necesidad de que en la investigación de actos criminales ejecutados por militantes de movimientos antiglobalización, la justicia opere a plenitud y no se permita fracasos como los ocurridos durante el dramático otoño de 1977, Hipp (2007).

${ }^{14}$ Información obtenida en Padtberg (2003). 
dad alemana ${ }^{15}$, así como otras 120 heridas, con graves secuelas físicas y sicológicas. Mientras, en lo cualitativo, la RAF reunió los rasgos paradigmáticos del terrorismo de la década de los 60 y 70; joven, urbano, provocador, osado $^{16}$.

Nacida en el seno de una generación altamente motivada por cuestiones políticas, no sólo por la influencia mundial del movimiento anti-intervención en Vietnam sino por el surgimiento en Alemania de una visión crítica respecto a la actitud de las generaciones anteriores frente al nacionalsocialismo, las proclamas insurreccionales de la RAF cautivaron a cientos de jóvenes, de estudiantes, de intelectuales y de artistas. La RAF hizo suyas las críticas juveniles al estado de bienestar y al estilo de vida burgués; demasiado egoísta a su juicio. El éxito del capitalismo en Occidente iba desmedro de los desposeídos de la Tierra.

${ }^{15}$ Entre las víctimas más prominentes de la RAF figuran: Siegfried Buback (Fiscal Federal General) 7 de abril de 1977; Jürgen Ponto (presidente del directorio del Dresdner Bank y asesor del canciller Helmut Schmidt) 30 de julio de 1977; Hans-Martin Schleyer (presidente de la Unión de Industriales de Alemania) 5 de septiembre de 1977; Andreas Baron von Mirbach (agregado militar alemán en Estocolmo) 24 de abril de 1975; Gerold von Braunmühl (director de Política General del Ministerio de Relaciones Exteriores) 10 de octubre de 1986; Alfred Herrhausen (presidente del Deutsche Bank y asesor del canciller Helmut Kohl) 30 de noviembre de 1989) y Detlev Karsten Rohwedder (presidente de la Agencia Fiduciaria de la ex RDA) 1 de abril de 1991, entre otros; véase Hipp et al. (2007).

${ }^{16}$ Según la policía alemana, la edad promedio del grupo en el momento de su clímax en 1977 era 27 años. El origen de la RAF data de abril de 1968, cuando un grupo de jóvenes, dirigidos por Andreas Baader y Gudrun Esslin, atenta con artefactos incendiarios contra la tienda de retail Springer Kaufhaus de Frankfurt, desatando un clima de efervescencia política nunca antes vista en la era postbélica. Ambos fueron arrestados y dejados en libertad a los pocos días debido a las crecientes protestas estudiantiles, que alcanzaron un importante clímax en las semanas posteriores al morir en un enfrentamiento con la policía el estudiante Benno Ohnesorg. Una decisión judicial posterior que reabrió el proceso fue rechazada por los imputados, quienes junto a su abogado, Horst Mahler pasaron a la clandestinidad, llamado a crear un grupo de guerrilla urbana al estilo tupamaro. Baader fue nuevamente arrestado, pero el 14 de mayo de 1970 logró huir tras una coartada conseguida con la periodista Ulrike Meinhof, quien también pasó a la clandestinidad y se unió al grupo. Tras este episodio proliferaron los asaltos a bancos y atentados contra instalaciones policiales y militares. El 5 de junio de 1970, la RAF emitió su primer comunicado llamando a crear un Ejército Rojo. Ese año, la plana mayor - a lo menos 18 dirigentes - se trasladó a Jordania para entrenarse con combatientes de Al Fatah y del Frente Popular de Liberación de Palestina. De vuelta en Alemania, el grupo multiplicó sus ataques hasta la detención en 1972 de Baader, Meinhof, Esslin y otros. Huelgas de hambre, denuncias de "torturas por aislamiento", exigencias de tratamiento como "prisioneros de guerra" y el suicidio de Holger Meins en su celda, así como la decisión de connotados juristas de asumir la defensa de los líderes de la RAF caracterizaron los años siguientes. A fines de 1976 adquirió enorme resonancia el suicidio de Ulrike Meinhof en la cárcel de Stuttgart-Stammheim, por una depresión 
Por ello no extraña que parte importante de la población juvenil alemana haya comenzado a mirar con arrobo casi extático a los grupos extraparlamentarios y que sus simpatías hayan sido atraídas por la extraordinaria fuerza gravitacional que tenían por aquel entonces los movimientos tercermundistas, especialmente la guerrilla urbana sudamericana, y aquellos de liberación nacional en los países árabes. Que la RAF haya alcanzado con ellos una conexión, a todas luces proterva, fue la externalidad obvia de tal tendencia. Un entorno de tales características sirvió a un grupo poco numeroso, pero radicalizado y de corte mesiánico, como aliciente para sentirse a sí mismo vanguardia de la revolución mundial; un compacto portador de la herencia insurreccional de Guevara.

Daniel Cohn-Bendit, actual euro-diputado por los Verdes, sobreviviente de aquel activo movimiento antisistémico conocido como Sponti-

provocada por acusaciones de Ensslin respecto a su "debilidad" para enfrentar los rigores de la "lucha desde la cárcel”. En el otoño de 1977 emerge la llamada segunda generación de la RAF con Christian Klar y Brigitte Mohnaupt a la cabeza y caracterizada por actos extraordinariamente sanguinarios, motivados por el deseo de forzar la liberación de los detenidos. Aparte de los asesinatos de altas autoridades del Estado, adquiere relevancia el secuestro del avión Landshut, de Lufthansa, el 13 de octubre de 1977 por parte de un comando conjunto de la RAF y el Frente Popular de Palestina, el cual desvían a Mogadishu, Somalia, donde unidades de elite alemanas (el GSG9) logran liberar el día 18 del mismo mes a los 86 rehenes (el piloto de la nave había sido asesinado durante una escala previa). En la misma noche del fracaso del secuestro, se suicidan en sus respectivas celdas, Baader, Esslin y Rasper. El industrial Schleyer que se encontraba secuestrado, es asesinado y su cuerpo abandonado en la localidad francesa de Mülhausen. Un último y fallido atentado ejecutado por esta segunda generación fue contra el comandante en jefe de la OTAN, Alexander Haig en Bélgica. Una debilitada tercera generación intenta retomar la actividad del grupo a fines de los 80 colaborando con otras organizaciones terroristas como la francesa Action Directe y la italiana Brigate Rosse. En 1985 asesinaron al presidente del grupo empresarial MTU y a un soldado norteamericano, al año siguiente a un alto ejecutivo de la Siemens, en 1989 al presidente del Deutsche Bank, Alfred Herrhausen, y en abril de 1991 al presidente de la Sociedad Fiduciaria de los bienes de la antigua RDA, Detlev Karsten Rohwedder, en lo que fuera la última acción terrorista del grupo. La mayoría de los arrestados purgaron y aún purgan largas penas, algunos han solicitado indultos presidenciales por estado de salud crítico. La única que nunca fue arrestada y de la que se ignora su destino es Friederik Krabbe, integrante del comando que asesinó a Schleyer. Investigaciones de prensa, citando fuentes de inteligencia alemanas y palestinas, han señalado que se refugió en Bagdad a partir de 1977 y años más tarde se habría casado con Abu Ibrahim, líder de un grupo terrorista árabe. Datos extraídos de Hipp et al. (2007), Bedürftig (1996) y Tackrah (2004). Otro impactante testimonio es la entrevista al terrorista Christian Klar "Ich bin nicht bereit, die RAF als Kriminalfall zu besprechen" (No estoy preparado para examinar a la RAF como un caso criminal), Freitag 51, www.freitag.de. En ésta se refiere con admiración a la experiencia allendista en Chile. 
Szene ${ }^{17}$, y recordado por su combativo apodo de entonces, "Dani el Rojo”, ha caracterizado a Andreas Baader con las siguientes palabras: "se trataba esencialmente de un tipo arrogante, con dotes de líder, y absolutamente convencido de que jugaría un papel central en la revolución mundial que acaecería en los años siguientes. Todos los que nos identificábamos como Sponti no deseábamos seguir con ese mundo tal cual era, queríamos contribuir a gestar uno nuevo y adoptamos el marxismo por su capacidad de crítica al capitalismo. Por lo mismo nos llamaban más la atención figuras como Che Guevara o el vietnamita Ho Chi-Minh. A través de ellos proyectábamos nuestros deseos de liberación y emancipación. Yo me explico el surgimiento de la RAF a través de la siguiente constatación, los principales grupos se formaron en Alemania, Japón e Italia, justo los tres países del eje, los países con pasado fascista. En el caso alemán, era necesario recuperar el tiempo perdido por la generación anterior en cuanto a la lucha antifascista. Sin embargo, nadie entre los Sponti supo distinguir a tiempo que el concepto de resistencia es distinto en un régimen fascista que en uno democrático"18.

Tales ideas e ideales, que a primera vista pudieran parecer plausibles, o a lo menos explicables en función del quiebre generacional que comenzaron a vivir las sociedades capitalistas occidentales en los sesenta, no tardaron en ser instrumentalizados por los servicios de inteligencia del mundo comunista, especialmente por la KGB y la Stasi. Una conexión lógica, toda vez que la osadía de la RAF parecía muy útil para el propósito de debilitar a las principales potencias capitalistas. La RAF podría no haber respondido al patrón leninista deseado por Moscú, pero su actitud insu-

${ }^{17}$ Sponti-Szene, Sponti-Bewegung o Sponti-Milieu es la denominación de un heterogéneo movimiento juvenil contestatario y extraparlamentario que adquirió preeminencia a comienzos de los 70 como resultado de las manifestaciones estudiantiles de los años previos. El nombre deriva del objetivo en común que tenían las diversas organizaciones "canalizar la espontaneidad de las masas". Éste fue el entorno que sirvió a la RAF para reclutar a sus integrantes, pero también le sirvió como masa crítica para la fuerte discusión sobre temas ideológicos que tanto importaban a la izquierda de aquellos años. Entre los principales grupos figuraban: Oposición Extraparlamentaria (APO, por sus siglas en alemán), Movimiento del 68, Grupos K (nombre derivado de Kader, cuadro, concepto leninista para señalar un grupo de elite revolucionaria), Tupamaros Westberlin y muchos otros. Entre los grandes líderes Sponti estaban Daniel Cohn-Bendit, Joschka Fischer (quien posteriormente surgió como principal dirigente verde y de la llamada tendencia Realo de este partido, llegando a ser ministro de Relaciones Exteriores bajo el gobierno del socialdemócrata Gerhard Schröder), así como el carismático Rudi Dutschke. Este último recibió un homenaje póstumo del movimiento universitario anti-globalización de Berlín al lograr que la municipalidad le pusiera su nombre a una céntrica calle (Hipp et al., 2007).

${ }^{18}$ Entrevista a Daniel Cohn-Bendit, en Sontheimer (2007). 
rrecta, su discurso tercermundista y, sobre todo, su inclaudicable fragor anti-establishment, la convertían en un interesante alfil del tablero global. Después de todo, Marx y Lenin habían lanzado, cada uno por su cuenta, apotegmas inequívocos respecto a que la violencia era la "partera" de la historia. Morgenthau dixit, Moscú y sus satélites establecieron una solidaridad ideológica con la RAF y otros grupos terroristas de Europa occidental $^{19}$. Especial vinculación desarrolló con ellos la Stasi germano oriental, lo que quedó en evidencia tras el fracaso del atentado contra el secretario general de la OTAN, Alexander Haig, en Bruselas en junio de 1979, que obligó a la cúpula de la RAF a organizar un importante repliegue. Algunos de sus miembros se instalaron en Irak, otros en Yemen. Y mientras los diez más buscados organizaban presurosos su huida hacia Mozambique, la Stasi entró en acción aconsejándoles no viajar al continente negro, ya que en África serían fácilmente identificables. A cambio, les ofreció asilo en la $\mathrm{RDA}$, dotarlos de nueva identidad, abrirles la posibilidad de rehacer sus vidas individualmente mediante la creación de historias ficticias y garantías de mantener contacto entre sí, en calidad de "célula dormida", hasta que la cúpula determinase su inclusión en algún nuevo objetivo. La tranquilidad de este pequeño grupo exiliado en la RDA se vio interrumpida bruscamente con la caída del muro de Berlín. El 6 de junio de 1990, la policía de la RDA, completamente reorganizada, descubrió la verdadera identidad de Ingrid Becker, como se hacía llamar Susanne Albrecht, la coautora del asesinato del industrial Jürgen Ponto. En pocos días logró detener a los otros miembros de la RAF que allí se escondían. Los diez fueron entregados en calidad de trofeo a la justicia alemana para su procesamiento. El sino fatal de este pequeño grupo también ya ha sido objeto de interés artístico, como lo revela el film de Volker Schlöndorff, "Die Stille nach dem Schuss"20.

Podría decirse que las miradas benignas —y por supuesto las artísticas- están dirigiéndose lentamente hacia las tres grandes singularidades del grupo. Uno, el entrecruce de bizarras historias de amor entre sus jóvenes protagonistas, compartiendo vivencias extremas y por tanto susceptibles de ser extrapoladas y estudiadas bajo diversas ópticas. Ejemplo de ello son las múltiples relaciones de pareja visibles entre los líderes, como Grudrun Esslin con Andreas Baader, o Peter-Jürgen Boock con Brigitte Mohnhaupt, y la más enigmática de todas, aquella entre el terrorista Karl-Heinz

\footnotetext{
${ }^{19}$ Morgenthau la utiliza para explicar las alianzas que resultan entre estados que comparten ciertos rasgos (políticos, culturales) que estimulan la identificación de imperativos comunes. La pertinencia de la paráfrasis está dada por aparición de diez terroristas de la RAF en la RDA tras la caída del Muro de Berlín. Morgenthau (1997).

${ }^{20}$ Conocido como "The Legend of Rita", estrenada en 2000.
} 
Dellwo y Susanne Albrecht, hija del conocido e influyente abogado de Hamburgo, Hans-Christian Albrecht, estrecho amigo del industrial Jürgen Ponto, asesinado en su propia casa por un comando del que formaba parte Susanne. Una segunda singularidad, aparentemente percibida como la principal si se tiene ante sí el listado de aproximaciones artísticas ya realizadas, dice relación con aquella opción vital, tan personal, de Ulrike Meinhof de abrazar una existencia entregada a la revolución abandonando un matrimonio estable (con dos hijas) y una vida relativamente ordenada, que en apariencias se mantenía dentro de los cánones tradicionales de la época; ein bürgerliches Leben ${ }^{21}$. En esta línea se ubica la narrativa fílmica de Schlöndorff, centrada en la tragedia personal de la terrorista Inge Viett debido al shock entre su visión naive de la lucha antiimperialista y las sinuosidades del socialismo real.

Luego, una tercera singularidad, donde hay materia prima potencialmente fuerte para los literati, radica en esa férrea disciplina, tan extraña a la juventud, y que este grupo mantuvo cuasi intacta entre sus tres generaciones. Una disciplina que le permitió obstaculizar a la justicia y al servicio de contra-inteligencia interior alemán, el Bundesamt für Verfassungsschutz.

Es altamente probable que en el futuro también adquiera interés otra gran singularidad del grupo, y hasta cierto punto excepcionalidad, que refuerza la idea de las individualidades fuertes que primaron en su interior,

${ }^{21}$ Nacida en 1934, trabajó desde 1959 a 1969 en la revista de izquierda Konkret, siendo desde 1964 su editora general. Trabajó también como guionista de algunos documentales políticos. En 1961 se casó con el propietario de la revista, Klaus-Rainer Röhl, con quien tuvo dos hijas mellizas, Regine y Bettina. En mayo de 1970, organizó la liberación de Andreas Baader y participó posteriormente en numerosos asaltos a bancos y atentados, siendo arrestada el 15 de junio de 1972 y condenada el 24 de noviembre de 1974 a ocho años de prisión. El 9 de abril de 1976 se suicidó ahorcándose en su celda en la ciudad de Stuttgart donde cumplía condena. A partir de ese momento, se ha indagado profundamente sobre las motivaciones de su auto-eliminación. En documentación de la RAF encontrada en las celdas de Andreas Baader y Gudrun Esslin destacan acusaciones internas del grupo en su contra debido a su presunta “debilidad” ideológica. Informes periciales revelan que Meinhof padecía fuerte depresión en el momento de su muerte. En 2002, su hija, la periodista Bettina Röhl descubrió que el cadáver de su madre había sido enterrado sin su cerebro y que éste se encontraba en una clínica universitaria. Meses más tarde obtuvo autorización judicial para enterrar el cerebro en el mismo féretro en que se encontraba el cuerpo. Su vida ha sido llevada al cine: "Marianne and Juliane” de Margaret von Trotta, "Stammheim” de Reinhard Hauff, a obras de teatro: "Ulrike Meinhof" estrenada en Bremen en 1990, "Ulrike Maria Stuart” escrita por la Premio Nobel Elfriede Jelinek en 2006 y estrenada en Hamburgo, así como también ha sido motivo de canciones: “To Ulrike M” del grupo pop sueco Doris Days, "Für Ulrike” del grupo pop de la RDA Aufbruch y "Cross the tracks” del grupo alemán Freundeskreis. Datos extraídos de Hipp et al. (2007), Bedürftig (1996) y Tackrah (2004). 
cual es el haber tenido una muy amplia composición femenina ${ }^{22}$. Así entonces, mientras en el caso de Guevara se divisa una proyección masculina hacia situaciones límites, Meinhof, Viett, Essling, Mohnhaupt y otras representan la individualización femenina de la insurrección.

\section{Los suicidas místicos: credo ergo sum}

En la mañana del 11 de septiembre de 2001, grupos de jóvenes suicidas islámicos desviaron simultáneamente varios aviones de vuelo comercial para estrellarlos contra dos símbolos del capitalismo, las Torres Gemelas y el Pentágono, provocando el mayor espanto terrorista contemporáneo. Aparentemente estos ataques fueron organizados y perpetrados por al-Qaeda, un grupo hasta entonces desconocido para el grueso de la opinión pública, incluso para segmentos relativamente informados. Al-Qaeda había sido hasta ese momento objeto de atención muy acotada. La información disponible sobre sus orígenes, sus líderes, sus ámbitos de acción, era ante todo imprecisa cuando no enteramente desconocida.

Sin embargo, estos ataques simultáneos cambiaron profundamente la percepción de peligros, de quiebres y de clivajes de carácter civilizacional existente hasta ese momento. Desde entonces, nada es como fue. Las agendas multilaterales, las normas de seguridad en el transporte de personas y carga, las prioridades de los servicios de inteligencia y policiales en todo el mundo, y de manera muy central la forma cómo EE.UU. se relaciona con el resto del mundo, tuvieron una profunda transformación.

Incluso, la episteme ${ }^{23}$ de los estudios internacionales cambió de manera importante, observándose un debate teórico profundo acerca de, por ejemplo, cuán disruptivo es el fenómeno del terrorismo en la naturaleza de

${ }^{22}$ Bajo el título "El Feminado Cruel” (Das grausame Feminat), el periodista Michael Sontheimer escribió un agudo reportaje acerca del rol jugado por las mujeres en la conducción del grupo concediéndole una importancia central a Ulrike Meinhof (autora de todas las proclamas del grupo hasta la fecha de su suicidio), a Gudrun Esslin (verdadera conductora política de la llamada primera generación, labor que siguió desempeñando incluso desde la cárcel) y a Brigitte Mohnhaupt (líder indiscutida de la segunda generación, considerada la terrorista más peligrosa que haya tenido el grupo y autora de los disparos de gracia que recibían las víctimas en la mayoría de los casos); datos extraídos de Sontheimer (2007). Un excelente video-reportaje, elaborado por la periodista de Die Zeit, Tanja Seltzer, denominado "Die Waffen der Frauen" (Las armas de las mujeres) en el sitio web del periódico www.zeit.de/video. En esta línea se enmarca también el film "Die bleierne Zeit” de Margaret von Trotta, centrado en la vida de Gudrun Esslin.

${ }^{23}$ En el sentido de Foucault, quien utiliza este concepto de manera similar al de paradigma, de Thomas Kuhn, pero otorgándole un matiz diferenciador que incluye aspectos no estrictamente necesarios para la reflexión científica, como son las percepciones sociales, culturales, así como los tipos de discursividad existentes en un período determinado, Foucault (1980). 
las relaciones internacionales contemporáneas ${ }^{24}$. La gran pregunta parece ser, ¿̇emana de estas amenazas no convencionales, y de estos nuevos clivajes internacionales, un caos sistémico mayor al inherente a las relaciones internacionales? No hay respuestas categóricas, pero sí existe una percepción extendida en torno a que los grupos proclives a la violencia política, al uso del instrumento terrorista, están adquiriendo rasgos novedosos que acentúan su carácter irregular. El terrorismo neomoderno pasó a caracterizarse por un creciente carácter trasnacional, alta letalidad, poderoso basamento religioso y nacionalista, elevada frecuencia en uso de suicidas y marcada orientación antioccidental ${ }^{25}$.

Si se intenta detectar qué tan herostratianos son estos grupos movidos por la fe en relación a que aquellos que lo hacen por la ideología, encontraremos una importante singularidad. Los terroristas revolucionarios, de inspiración guevariana, son más terrenales y menos místicos, se ven a sí mismos más como colectivos, formados por individualidades, que como una masa hundida en el anonimato. Pareciera que pese a su irrefrenable impulso insurreccional y a sus infinitas diatribas contra el estado burgués, el terrorista revolucionario no ha dejado de ser un producto cultural de Occidente.

Debido al valor de la individualidad y a la convicción explícita o implícita de que el cambio que se procura es una tarea a realizar aquí en la Tierra, por los hombres y para los hombres (entendido genéricamente), el suicidio místico fue (y muy probablemente siga siendo por largo tiempo) ajeno al terrorismo latinoamericano y europeo, y el suicidio místico terminó enraizando en los grupos fundamentalistas islámicos.

¿Qué razones podrían explicar esta confluencia entre las visiones radicalizadas del Islam y el neoterrorismo que tanto espanto causa en Occidente?26.

Un primer asunto relevante es el hecho irrefutable de que el islamismo vive un creciente florecimiento político, muy asociado, por un lado, a la redención social (Hezbollah) y, por otro, a la redención nacional (Hamas); ambas, manifestaciones paradigmáticas del neoterrorismo. Dicho florecimiento está dado por varias circunstancias, para nada contradictorias entre sí, entre las que destaca la desaparición de un actor global, la Unión Soviética, considerado aliado por una cantidad importante de países islámicos, cuyo impacto concreto es observable en el hecho de que numerosos militantes del nacionalismo marxista panárabe se convirtieron rápidamente a una mortífera variante del islamismo radical. Este proceso explica el eclipse

\footnotetext{
${ }^{24}$ Waltz (2002).

25 Witker (2005).

${ }^{26}$ Una vasta e interesante discusión bibliográfica sobre la conexión entre acción violenta y religión e ideología en Trujillo (2006) y Peregrin (2007).
} 
de la Organización para la Liberación Palestina (OLP) y del pro soviético Frente Popular de Liberación de Palestina, de Georges Habasch, FPLP), así como también (y en contraoposición a lo anterior) la vigorización de Hamas. Luego, otra circunstancia con vasta capacidad explicatoria es el surgimiento de una república islámica en Irán, país gravitante en su espacio geopolítico, cuyos ayatollahs se autoasignaron la tarea de asistir a los más diversos movimientos islamistas anti-Occidente, desatando una actitud vital a favor del terrorismo suicida denominada espíritu bassitchi ${ }^{27}$.

Dado que el espíritu bassitchi conlleva una fuerte dosis sacrificial, de servicio a una causa superior, el régimen de Teherán creyó posible asociarlo al espíritu guevarista en el contexto de su ofensiva diplomática hacia América Latina ${ }^{28}$, haciendo esfuerzos reales por encontrar similitudes, en especial con el ejemplo del comandante Mostafá Chamran, considerado la figura excelsa del espíritu bassitchi ${ }^{29}$.

${ }^{27}$ Derivado de la expresión persa bassitchi e mostadafan (los movilizados de los explotados), utilizada para denominar una milicia fanática iraní integrada por adolescentes entre 12 y 15 años de edad preparados para enfrentar como suicidas los rigores de la Guerra del Golfo. Desde entonces son entrenados por batallones de elite, pasdaran, y suelen ser reclutados en las escuelas sin necesidad de aprobación paternal. Durante el conflicto con Irak formaron las llamadas "olas humanas", un ataque táctico destinado a desminar ciertas zonas y prepararlas para el combate cuerpo a cuerpo o para el avance de blindados. En agosto de 1983, soldados iraquíes capturaron más de 200 muchachos bassitchi y entregaron información a la ONG Terre d’Hommes que elaboró un informe para Naciones Unidas. Una cantidad indeterminada de jóvenes de esta milicia fueron enrolados en Hezbollah después de finalizar la guerra Irán-Irak, con la finalidad de servir de ejemplo y fortalecer el espíritu bassitchi en ese grupo irano-libanés. En la actualidad dirige esta milicia el comandante Mohammed Hejazi; tiene una estructura altamente descentralizada estando presente en casi todas las mezquitas del país. Es utilizada hoy principalmente para reprimir a minorías religiosas, sobre todo de la secta sufí, Krauze (2007) y Ortiz (2006).

28 Desde el año 2005, Irán lleva a cabo una auténtica ofensiva hacia América Latina que consiste en abrir embajadas en Chile, Nicaragua, Bolivia y Ecuador, así como en fortalecer nexos políticos, militares y económicos con Venezuela. El propio Presidente M. Ahmedinejad ha viajado en varias oportunidades por los citados países latinoamericanos.

${ }^{29}$ Shemuel Even y Shaul Kimhi han desarrollado una tipología específica de las motivaciones de los suicidas palestinos que goza de gran reconocimiento por estar basada en fuentes primarias. Los prototipos estudiados por Kimhi y Even son: el religioso, el sicológicamente devastado, el nacionalista, el manipulado y el circunstancial (random). Se ha desarrollado también la siguiente tipología de suicidas místicos, según la forma de perpetrarlos: a) aquel que provoca un atentado y enseguida se suicida (por lo general porta un arma que le sirve para la autoeliminación, b) aquel que se autoelimina para provocar un atentado (por lo general porta una carga explosiva), c) la bomba $\mathrm{H}$, aquel terrorista que se sitúa en el lugar del atentado para ser eliminado mediante una descarga a control remoto o por una bomba de tiempo adherida, d) aquel que es eliminado por un compañero de ataque como parte de la estratagema. Su monografía "The Palestinian Suicide Bombers" fue presentada en 19 Congreso Mundial de Ciencia Política, Durban, 2003, y es discutida in extenso en Witker (2005). Una reflexión extraordinariamente asertiva sobre el impacto del terrorismo suicida en el conflicto palestino-israelí en Luft (2002) 
Se trata de un político y científico iraní que tras sus estudios en EE.UU. se integra a la revolución de Khomeini y marcha luego al Líbano a combatir contra Israel en las filas de Amal, y a formar células shiitas que darían vida a Hezbollah, yendo más tarde a organizar otros grupos similares a Egipto, para volver a Irán, donde en su calidad de ministro de Defensa marchó al frente de la guerra contra Irak falleciendo en combate en $1981^{29}$.

La azarosa vida de ambos, en el entendido que fueron consagradas de manera fulminante a la revolución mundial, sus escritos y el recuerdo de sus cercanos, constituyeron tema central de un seminario que organizó la Universidad de Teherán entre el 25 y 29 de septiembre de 2007 y al que asistieron como panelistas dos hijos del guerrillero argentino-cubano. El seminario, que no tuvo el epílogo deseado, terminó constatando la imposibilidad de visualizar puntos en común entre un ateo y un shiita.

Más aún, ese desencuentro entre Guevara y Chamran explica por qué el uso tan masivo e indiscriminado de suicidas místicos puede multiplicarse en ambientes dominados por el islamismo fundamentalista y no en Occidente, donde incluso las experiencias más traumatizantes (como la de Guevara en su tiempo) no dejan de tener en consideración las facetas individuales implícitas. Hay algo de deshumanización elemental en las experiencias radicalizadas del Islam que provocan un rechazo ab intra. Explica, además porque ni sus protagonistas más destacados son asumidos como individualidades que derrochen carisma. Son seres que no irradian magnetismo. Y al no existir individualidades fuertes, no hay elementos susceptibles de ser procesados como mito. La terrible letalidad de sus actos impide convertirlos en objetos de culto.

En consecuencia, los terroristas suicidas, incluyendo el dramático caso de las mujeres ${ }^{30}$, buscan (o les impone el medio) una trascendencia

${ }^{29}$ Nacido en 1932 en Teherán, estudió ingeniería en Electrónica en la University of Texas en Houston, Texas, y tras su doctorado en Berkeley trabajó en el Jet Propulsion Lab de la NASA para irse luego por ocho años a ejercer como rector del Instituto Tecnológico Dschabal-Amal en el sur del Líbano. Pese a ser ministro de Defensa, dedicó sus mayores esfuerzos durante la guerra Iran-Irak a formar las milicias paramilitares conocidas como Pasdaran.

30 Éste es un caso tan dramático como el de los niños suicidas. Un paper de extraordinario valor por el trabajo con fuentes primarias corresponde a "Female Suicide Bombers" elaborado por la consultora británica Medea Group. Innovative, Security and Development. El estudio indaga sobre casos de mujeres suicidas en Palestina. Chechenia, Pakistán, Afganistán e Irak, principalmente, estableciendo que entre 1985 y 2006, 225 mujeres se han convertido en suicidas místicos. Siguiendo este estudio, el primer registro corresponde a la libanesa de 17 años Sana Mahaydali, militante del Partido Socialista Sirio que se hizo explotar en la frontera con Israel el 9 de abril de 1985. En el listado sorprende la ciudadana belga Muriel Degaque, única occidental, casada con un militante 
algo distinta de la de Guevara y Meinhof; no es terrenal. Al padecer patologías tan severas como inocultables, no están dotadas de ese perverso glamour de Guevara o los líderes de la RAF. Y aun cuando a todos ellos les gusta jugar con la muerte y con la sangre, los insurrectos revolucionarios se diferencian de los suicidas místicos por darle a su lucha un sentido depurador de la existencia directamente sobre la faz de la Tierra y no en algún edén metafísico. La lucha para Guevara y Baader es colectiva, pero no va en detrimento de la individualidad, no ahoga la realización personal. Aún más, lo colectivo es visto como una suma de individualidades. Por lo mismo, en los suicidas místicos se advierte menos autenticidad, escasos elementos genuinos. Y lo se percibe en tan terribles experiencias es la presencia activa de una mano planificadora, adoctrinadora, adiestradora, que paga por el servicio, y que ve en los suicidas sólo una masa inerte ${ }^{31}$.

\section{Conclusiones}

Si bien el camino de la violencia política contemporánea, que va desde Guevara hasta los suicidas místicos, apunta a la búsqueda herostratiana de alcanzar fama imperecedera basada en acciones que conllevan sacrilegi $^{32}$, se observan en ella bifurcaciones importantes que se desprenden de la relación individuo/ambiente y del entorno donde se genera el mensaje del terrorista. Por eso, Guevara, Ulrike Meinhof e Inge Viett son parte de la cultura occidental y susceptibles de ser rescatados como individuos entregados a una causa (justa), con fuerzas y debilidades propias. Tal rescate es posible por la convergencia de la democracia con la economía de mercado en un contexto cultural occidental, el mismo que, en su afán de procesar eventos inesperados, observa, examina, e incluso acoge culturas adversativas.

Los terroristas suicidas, en cambio, son hijos de visiones absolutas y productos culturales tipo credo ergo sum, que privilegian los caminos

islámico fundamentalista de origen marroquí, que se suicidó violentamente en el foyer del Hotel Amman de Bagdad el 9 de noviembre de 2005. Igualmente impacta la constatación de que gran parte de ellas estaban embarazadas en el momento de cometer suicidio. En el caso checheno, muchos de las ataques suicidas entre 2002 y 2004 fueron cometidos por esposas de hombres fallecidos en combate contra los rusos. Esta brigada de mujeres suicidas se denominó "Viudas de Negro" (Medea Group, 2007). Información adicional en Moghadam (2005).

${ }^{31}$ Aunque el trabajo Atran (2003) tiene carácter seminal, se considera a Moghadam (2005), Ganor (2007) y Wiewiorka (2007) como las principales referencias especializadas.

${ }^{32}$ De acuerdo a la reflexión de Borowitz (2005). 
místicos, la inmolación masiva, anónima e indiscriminada. Se someten servilmente a un tipo de racionalidad que demanda gestos maximalistas imposibles de iconizar.

El síndrome de Herostratos, entendido como un afán de trascendencia, es mucho más perceptible en Guevara y en Meinhof. Por eso, tal como la noche de un 356 a.C., en que ocurrió el incendio del templo a Artemisa, habría nacido Alejandro Magno, el dramático fin de Guevara en Ñancahuazú y de la cúpula RAF en Stuttgart-Stammheim, más allá de la acritud y dramatismo de la circunstancia, fue visto en su entorno como el parto de un mañana mejor. Después de todo, Guevara y Meinhof se veían a sí mismos como prototipos del "hombre nuevo".

Guevara, Baader y Meinhof murieron convencidos que su fin no sería anónimo. El heroísmo con que intentaron impregnar su extremismo político era esencialmente individual y siempre lo vieron como algo ejemplar. En consecuencia, murieron en el convencimiento de que el Estado burgués terminaría siendo reemplazado, tarde o temprano, por otro con el que soñaron en su intimidad, y en la certidumbre que serían recogidos como individuos heroicos.

El factum central es, en todo caso, que nunca imaginaron un capitalismo devenido en sistema de alcance mundial, vigoroso, dominado por la democracia y la economía de mercado, que si bien los rescató individualmente, fue por la vía de transformarlos en mitos, en objetos de culto mercantilizados.

\section{BibLIOGRAFÍA}

Amzol, Stefan (entrevista a Christian Klar): "Ich bin nicht bereit, die RAF als Kriminalfall zu besprechen” (No estoy preparado para examinar a la RAF como un caso criminal). En Freitag 51, 21 de diciembre de 2007. Disponible en www.freitag.de.

Arendt, Hannah: Macht und Gewalt. München: Piper, 1970.

Atran, Scott: “Genesis of Suicide Terrorism”. En Review of Social Science, Vol. 299, 7 de marzo de 2003, University of Michigan,

Bedürftig, Friedemann: Lexikon Deutschlands nach 1945. Hamburg: Carlsen Verlag, 1996.

Borowitz, Albert: Terrorism for Self-Glorification: The Herostratos Syndrome. Kent (Ohio): The Kent State University Press, 2005.

Castañeda, Jorge: Compañero: The Life and Death of Che Guevara. N.Y.: Vintage, 2004.

Crenshaw, Marta: “Explaining Suicide Terrorism: A Review Essay”. En Security Studies, Vol. I, N 6 (Spring, 2007), pp. 133-162.

Foucault, M.: La Arqueología del Saber. México: Siglo XXI Editores, 1980.

Galtung, Johan: Strukturelle Gewalt. Beiträge zur Friedens-und Konfliktforschung. München: Reinbek, 1975. 
Ganor, Boaz et al.: Countering Suicide Terrorism. Jerusalen: IDC Herzliya, 2007.

Guevara, Ernesto: Guerra de Guerrillas. La Habana: Granma, 1970. Disponible electrónicamente en Granma Edición Internacional. Biblioteca de Textos Marxistas. www.granma.cu.

- Discurso pronunciado en la ONU, 11 de diciembre de 1964. Disponible en www.YouTube.com.

Hipp, Dietmar (entrevista a Monika Harms): "Wir betreiben keine Willkur” (No llevamos a cabo arbitrariedades). En Der Spiegel № 22, 26 de mayo de 2007.

et al.: “Genug der Sühne?” (¿Suficiente de penitencia?). En Der Spiegel $\mathrm{N}^{\circ} 5,29$ de enero de 2007.

Kimhi, Shaul e Even Shemuel: "The Palestinian Suicide Bombers: Tipology of Suicide Terrorist”. Trabajo presentado en el 19 Congreso Mundial de IPSA, Durban, Sudáfrica, 2003.

Krauze, Leon: “Un Islam Democrático. Entrevista con Fareed Zakaria”. En Letras Libres, mayo, 2007. Disponible en www.letraslibres.com.

Laqueur, Walter: "La Guerra sin Fin: El Terrorismo en el Siglo XXI”. Madrid: Ediciones Destino, 2002.

Lee Anderson, Jon: Che Guevara. Una Vida Revolucionaria. Madrid: Anagrama, 2006.

Luft, Gal: "The Palestinian H-bomb: Terror's Winning Strategy”. En Foreign Affairs, July-August, 2002.

Medea Group Innovative, Security and Development: Female Suicide Bombers: Practical Implications, Vol. II, № 2, 2007. Disponible en www.medeagrp.com.

Moghadam, Mostafa: The Roots of Suicide Terrorism: A Multi-Casual Approach. Trabajo presentado al Harrington Workshop on the Root Causes of Suicide Terrorism, 19 de abril de 2005. Disponible en www.ksg.harvard.edu.

Morgenthau, Hans: Politics among Nations. New York: Knopf, 1997.

Ortiz, Ximena: “Geopolitical Jihad”. En The National Interest № 83 (Spring 2006), Washington D.C.

Padtberg, Carola: “Terrormythos RAF”. En Die Zeit, 24 de julio de 2003. Disponible en www.zeit.de.

Peregrin, Fernando: "La Racionalidad en el Islam y en el Occidente”. En Bien Común, Nº 156 (diciembre 2007), Fundación Rafael Preciado, México D.F.

Polk, William: Violent Politics. A History of Insurgency, Terrorism and Guerrilla War, from the American Revolution to Iraq. New York: Harper Collins Publishers, 2007.

BBC News: “Guevara’s Image Saved from Drink”. BBC News 15 de septiembre de 2000. Disponible en: www.bbc.co.uk.

“Che Guevara Photographer Dies”. BBC News, 26 de mayo de 2001. Disponible en: www.bbc.co.uk .

Sontheimer, Michael (entrevista a Michael Buback): "Wie ein böser Traum” (Como un sueño maligno). En Der Spiegel N 30, 23 de julio de 2007.

- (entrevista a Daniel Cohn-Bendit): “Immer Radikaler” (Siempre más radical). En Der Spiegel N 39, 24. 9. 2007.

“Das grausame Feminat”. En Der Spiegel № 42, 15 de octubre de 2007.

Tackrah, John: Dictionary of Terrorism. Londres: Routledge, 2004.

Trujillo, Humberto et al.: "De la Agresividad a la Violencia Terrorista: Historia de una Patología Psicosocial Previsible”. En Psicología Conductual, Vol. 14, № 2 (2006), Universidad de Granada, España. 
Vargas Llosa, Álvaro: “La Máquina de Matar. El Che Guevara, de Agitador Comunista a Marca Capitalista”. En Letras Libres, febrero 2007, México D.F.

"El Mito del Cadáver del Che”. En El Diario Exterior 3 de noviembre de 2007. Disponible en: www.diarioexterior.com.

Waltz, Kenneth: "The Continuity of International Politics". En Ken Booth y Tim Dunne, Worlds in Collision. London: Palgrave Macmillan, 2002.

Wiewiorka, Michel: "From Classical Terrorism to 'global' terrorism”. En International Journal of Conflict and Violence, Vol. I, N 2, 2007, pp. 92-104.

Witker, Ivan: “Occidente ante las Nuevas Tipologías del Terrorismo”. En Estudios Públicos $\mathrm{N}^{\circ} 98$ (otoño 2005).

Palabras clave: violencia política; terrorismo; síndrome de Herostratos; Che Guevara; RAF (Rote-Armee-Franktion); terroristas suicidas.

Recibido: enero de 2008; aceptado: agosto de 2008. 